\title{
Effect of Imposed Shear Strain on Steel Ring Surfaces during Milling in High-Speed Disintegrator
}

\author{
Karel Dvořák ${ }^{1, *(1)}$, Adéla Macháčková ${ }^{2}$, Simona Ravaszová ${ }^{1}$ and Dominik Gazdič ${ }^{1}$ \\ 1 Faculty of Civil Engineering, Brno University of Technology, Veveří 331/95, 60200 Brno, Czech Republic; \\ ravaszova.s@fce.vutbr.cz (S.R.); gazdic.d@fce.vutbr.cz (D.G.) \\ 2 Faculty of Materials Science and Technology, VŠB-Technical University of Ostrava, 17. listopadu 15, \\ 70800 Ostrava, Czech Republic; adela.machackova@vsb.cz \\ * Correspondence: dvorak.k@fce.vutbr.cz
}

Received: 13 April 2020; Accepted: 11 May 2020; Published: 13 May 2020

\begin{abstract}
This contribution characterizes the performance of a DESI 11 high-speed disintegrator working on the principle of a pin mill with two opposite counter-rotating rotors. As the ground material, batches of Portland cement featuring 6-7 Mohs scale hardness and containing relatively hard and abrasive compounds with the specific surface areas ranging from 200 to $500 \mathrm{~m}^{2} / \mathrm{kg}$, with the step of $50 \mathrm{~m}^{2} / \mathrm{kg}$, were used. The character of the ground particles was assessed via scanning electron microscopy and measurement of the absolute/relative increase in their specific surface areas. Detailed characterization of the rotors was performed via recording the thermal imprints, evaluating their wear by $3 \mathrm{D}$ optical microscopy, and measuring rotor weight loss after the grinding of constant amounts of cement. The results showed that coarse particles are ground by impacting the front faces of the pins, while finer particles are primarily milled via mutual collisions. Therefore, the coarse particles cause higher abrasion and wear on the rotor pins; after the milling of $20 \mathrm{~kg}$ of the $200 \mathrm{~m}^{2} / \mathrm{kg}$ cement sample, the wear of the rotor reached up to $5 \%$ of its original mass and the pins were severely damaged.
\end{abstract}

Keywords: disintegrator; microscopy; wear; high energy milling; cement

\section{Introduction}

The necessity to enhance the utility properties of materials and increase the longevity of construction components has led research and development in various industrial branches, such as materials processing [1] or construction [2,3], towards the design of new materials and improving the performance of contemporary ones. Generally, enhancement of the mechanical and utility properties can be achieved via variations in the chemical composition of the particular material, as documented, for example, by Zhang et al. [4], and structural modifications (grain refinement), which was demonstrated also for pure and commercially pure metals $[5,6]$. Verlinden et al. claimed that grain refinement introduces lattice defects, such as dislocations and grain boundaries, which increase the materials' intrinsic energy and act as strengthening agents [7]. Kunčická et al. studied syntheses of various kinds of alloys and reported that the grain size can typically be decreased in two ways, the first of which is application of the the methods of intensive/severe plastic deformation (SPD) decreasing the grain size down to sub-micron scale via imparting severe shear strain [8] (e.g., equal channel angular pressing [9] and high-pressure torsion [10]). The second is the implementation of powder metallurgy, i.e., the production of materials from original powders, which is typically used for challenging materials, such as Ti composites [11] or tungsten heavy alloys [12]. Combinations consisting of the processing of challenging powder-based materials, such as Ti-based [13], and W-based [14] alloys, via SPD methods are also advantageous. 
The process of production of a component from powders involves final shape and surface treatments, which typically follow deformation processing and/or variations of sintering and heat treatments. The first production step is, however, preparation of the original powders. These are usually manufactured by milling. The grain size distribution and morphology of the grains have fundamental effects not only on the sintering process itself, as mentioned by Wang et al. [15], but also on the final structure of the alloys as described by Macháčková et al. [16]. Surzhenkov et al. studied the wear resistance and mechanisms of abrasion during milling. Based on the results of their research, it can be stated that the grain refinement in mills is typically ensured via several fundamental mechanisms, among which are compression, shear (attrition), compression pulse, impact (stroke or collision), impact and shear, tension/bending, splitting, and cutting. Milling can be performed by collisions of particles with the working tools, via mutual collisions between particles, or between particles and their environment [17].

Among the recent trends in milling is the high-energy milling (HEM) method. The possibilities of application of HEM are in various industrial fields, from milling of demanding composites in metallurgy, as documented, for example, by Muroi et al. [18] or Sazavi et al. [19], through fabrication of various intermetallic and ceramic materials, such as those mentioned by Serena et al. [20], to the preparation of nanomaterials (e.g., Rojac et al. [21]). High-speed grinding (HSG) is a particular type of HEM carried out by applying high amounts of energy using very short and intense power pulses. The amount of energy that is effectively transferred to the material is higher in HSG than in the case of conventional grinding in mills with identical power inputs. Among the types of mills suitable for HSG is a high-speed pin mill with two counter-rotating rotors, known as the disintegrator. This type of mill, the material in which is refined by high-frequency changes in mechanical strength, was extensively studied by Hint [22]. The disintegrator is particularly suitable for the grinding and activation of fine powder materials, as documented by Bumanis [23], and Bumanis and Bajare [24]. The principle of a disintegrator lies in accelerating the material to a high speed by means of the pins on the grinding rotor. The particles than collide with other particles or with the pins on the rotor which rotates in opposite direction. Disintegrators only use the impact, impact and shear, shear (attrition), and tension/bending mechanisms. However, other processes similar to those in attritors or jet mills occur as well. These are introduced by turbulent flow and rapid compression and expansion between the rotors, as described by Kovalev [25]. Baláž wrote in his study [26] that the main advantages of a high-speed disintegrator are continuity of the grinding process, and variety of working tools that can be employed. On the other hand, Surzhenkov et al. stated the main disadvantage to be that the grinding elements are prone to abrasion/wear [17].

Collisions of particles and hard surfaces can be advantageous since the shear strain introduced to the hard surface via the impacting particles typically induces the formation of hard structure phases at the surface of the base material (such as martensite for stainless steels as reported by Staman et al. [27]), by the effect of which the surface hardness increases, and the surface hardening consequently reduces the tendency of the base material (i.e., rotors) to abrasion/wear, as claimed by Silva et al. [28] and Han et al. [29]. On the other hand, continuous high-speed shelling of the base material (rotors) with hard and/or sharp-edged particles inevitably leads to abrasion/wear in time. Gåhlin and Jacobson [30] mentioned that the intensity of wear depends on the mineralogy, morphology, and granulometry of the ground material. However, the effect of particle size of the milled material on wear is not yet fully understood. Misra and Finnie [31] suggested that increasing the particle size increases the wear rate. Small particles lead to penetrations that do not pass through the surface layers of the grinding elements; according to the theory introduced by Larsen-Bads [32], sufficiently small particles are in elastic contact with the grinding tools and do not contribute to abrasion. The presupposed effect of particles' shapes on the degree of abrasion is based on a theory assuming that blunt shapes exert less pressure on the grinding tools and consequently act more like particles providing surface hardening via imposing shear strain and produce less wear than sharp-edged particles. For milled material featuring wider size fractions, the largest grains exert strong point loads on the surfaces of the grinding elements; i.e., such material is more abrasive $[17,30]$. 
If the pins are damaged due to abrasion, the efficiency of grinding is reduced. By this reason, the geometry of the milling elements is favourable to be kept constant for as long as possible during milling. The presented study is focused on characterization of the behaviour of rotors of a high-speed disintegrator during milling of a Portland cement, because the HSG technology seems to be a very effective milling technology, moreover, with the benefit of mechanical activation. However, certain issues in this field still remain uncovered. The standard Portland cement is relatively fragile and contains four main minerals with the average hardness of 6-7 (according to the Mohs scale). It features sharp-edged particles, which makes it a very abrasive material. Grinding by a disintegrator is also supposed to be very effective for this particular material since it responds very well in milling by impact or compression pulse [33]. The study is supplemented with characterization of correlations between entry granulometry and abrasion of the rotors during milling.

\section{Materials and Methods}

The equipment investigated is the DESI 11 disintegrator (Desintegraator Tootmise OÜ, Tallinn, Estonian Republic), which is a laboratory version of a high-speed pin mill with two counter-rotating rotors. The total installed output of the mill is $4.1 \mathrm{~kW}$. The rotor rotation frequency is up to $12,000 \mathrm{RPM}$, and the maximum circumferential speed of each rotor is $92.4 \mathrm{~m} / \mathrm{s}$. The material is fed into the device by a continuous feeder and enters the grinding chamber through the middle of the left rotor; a schematic depiction of the principle of the disintegrator is shown in Figure 1a, and also described in [17]. The real machine is presented in Figure 1b. The construction of the mill allows for a choice of working tools. For this experiment, the CR type rotors designed and manufactured by the FF servis s.r.o. company (Prag, Czech Republic) were used. The rotors were manufactured from C45 steel, sometimes also characterized as SI 1045 steel. This medium-carbon steel was selected for its high quality, relatively high strength, and easy machinability; the rotors were machined from normalized hot-rolled bars. The external diameter of both the rotors was $147 \mathrm{~mm}$. The left rotor has two rows, while the right rotor has three rows of $3 \times 3 \times 3 \mathrm{~mm}$ cubic pins. The designs of both the rotors are demonstrated in Figure $1 \mathrm{c}, \mathrm{d}$.

The Portland cement used for this experiment was prepared in a ball mill by collective milling of cement clinker (from Hranice cement plant) and chemical gypsum (Pregips), the chemical compositions of which are depicted in Table 1. The chemical composition of the selected clinker is typical for Portland clinkers. The gypsum (highly pure) contained relatively high humidity and it was further dried before milling to decrease the moisture to under $5 \%$. The ratio of clinker to gypsum was 95:5.

Table 1. Partial chemical compositions of the ground material.

\begin{tabular}{cccccccccc}
\hline \multirow{2}{*}{ Material } & \multicolumn{10}{c}{ Component } \\
\cline { 2 - 10 } & $\mathbf{S i O}_{2}$ & $\mathbf{C a O}$ & $\mathrm{Al}_{2} \mathbf{O}_{3}$ & $\mathbf{F e}_{2} \mathbf{O}_{3}$ & $\mathbf{S O}_{3}$ & $\mathrm{CaSO}_{4} \cdot \mathbf{2} \mathbf{H}_{\mathbf{2}} \mathbf{O}$ & $\mathbf{H}_{\mathbf{2}} \mathbf{O}$ & $\mathrm{CaSO}_{4}$ & Others \\
\hline Clinker & 20.29 & 65.33 & 5.21 & 5.04 & 0.79 & - & - & - & 3.34 \\
Gypsum & - & - & - & - & - & 84.0 & 11.0 & 2.4 & 2.6 \\
\hline
\end{tabular}

For the subsequent milling process, a set of seven individual batches with specific surface areas ranging from 200 to $500 \mathrm{~m}^{2} / \mathrm{kg}$ was prepared. The batches of cement with the selected granulometries were fed into the disintegrator continuously. The dosing rate was $5.5 \mathrm{~g} \cdot \mathrm{s}^{-1}$ and the cement particles are supposed to spend approximately 1 second in the milling chamber due to the pin mill principle. All the samples were milled at the maximum speed of 12,000 RPM.

Grinding of all the samples was carried out under standard laboratory conditions, at $22{ }^{\circ} \mathrm{C}$ and relative humidity of $56 \%$. After grinding of each $1 \mathrm{~kg}$ batch, thermal imprint on the rotor was acquired using a Flir E4 thermal camera (FLIR Systems Inc., Wilsonville, OR, USA). Between milling of the individual batches, the disintegrator was cooled by an air stream to the initial temperature of $22^{\circ} \mathrm{C}$ and the rotors were replaced with a new set. 


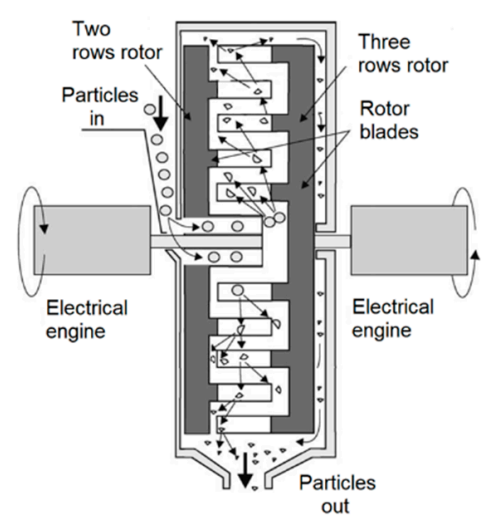

(a)

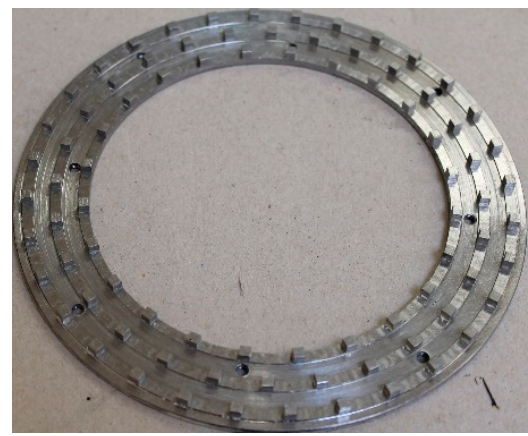

(c)

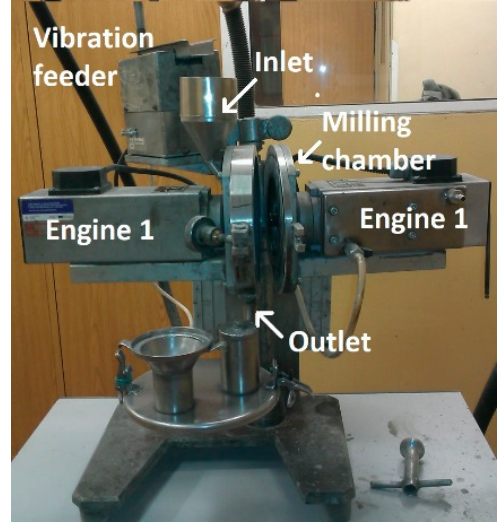

(b)

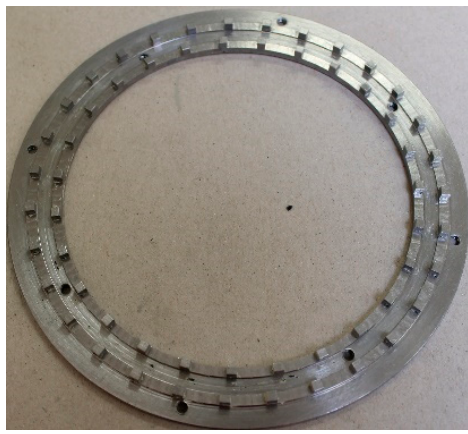

(d)

Figure 1. (a) Schematic depiction of the investigated disintegrator; (b) laboratory DESI 11 HSG mill (c) rotor with three rows of pins; (d) rotor with two rows of pins.

The increase in the Blaine specific surface area and the morphology of grains were determined for all the samples. The Blaine specific surface area was measured using a PC-Blaine-Star automatic device (Zünderwerke Ernst Brün $\mathrm{GmbH}$, Haltern am See, Germany) with a measuring cell with the volume of $7.95 \mathrm{~cm}^{3}$. Measurement was repeated three times and averaged to minimize errors. To evaluate the impact of the input granulometry on the abrasion of working elements, two $20 \mathrm{~kg}$ batches of cement were prepared in a ball mill. The first sample featured the specific surface area of $200 \mathrm{~m}^{2} / \mathrm{kg}$, while for the second one it was $450 \mathrm{~m}^{2} / \mathrm{kg}$. The milling parameters were identical as for the previous case; rotor speed of 12,000 RPM and dosing rate of $5.5 \mathrm{~g} \cdot \mathrm{s}^{-1}$.

The particle size and particle size distribution were determined for both the input samples using a Malvern Mastersizer 2000 (Malvern Panalytical B.V., Almelo, The Netherlands) with a Hydro 2000 G fluid dispersing unit, 2-isopropanol was used as a dispersing agent. The morphology and grain shapes were observed and assessed by scanning electron microscopy (SEM) using a Tescan MIRA 3XMU (Tescan Brno s.r.o., Brno, Czech Republic) equipment.

Evaluation of the abrasion-milling elements was performed via calculating the ratio between the weight of the eroded rotors after milling of 1,10 and $20 \mathrm{~kg}$ of abradant, and the initial weight of the rotors. The accuracy of the weight loss measurements was $0.01 \mathrm{mg}$.

Also, the impact of rotor wear on grinding efficiency was measured by monitoring the increase in the specific surface area of the cement. The abrasion of the rotors was also determined by 3D scanning. Detailed 3D scans of the rotor pins were performed and evaluated using an Olympus DSX1000 digital microscope (Olympus Czech Group, s.r.o., Prague, Czech Republic).

\section{Results}

Abrasion speed is not constant and depends on the input granulometry and on the shape of the ground particles. Morphology of the cement particles was investigated via SEM-BSE; images of the 
cement particles within the individual samples are depicted in Figure $2 \mathrm{a}-\mathrm{f}$ within which individual pairs of figures represent morphology of the samples before and after milling in the HSG mill. Figure 2a,d depict the samples with the initial specific surface area of $200 \mathrm{~m}^{2} / \mathrm{kg}$, whereas Figure $2 \mathrm{~b}$,e show the samples with the initial specific surface area of $300 \mathrm{~m}^{2} / \mathrm{kg}$, and Figure $2 \mathrm{c}, \mathrm{f}$ depict the samples with the initial specific surface area of $450 \mathrm{~m}^{2} / \mathrm{kg}$.

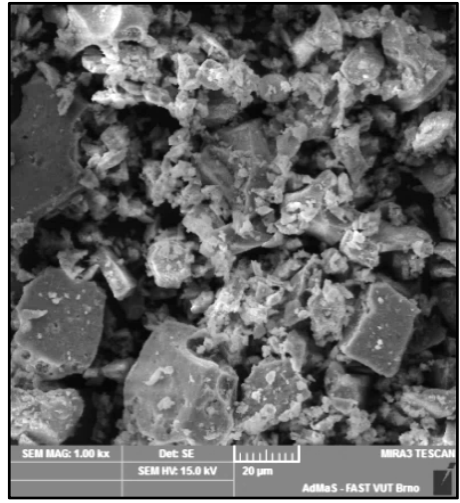

(a)

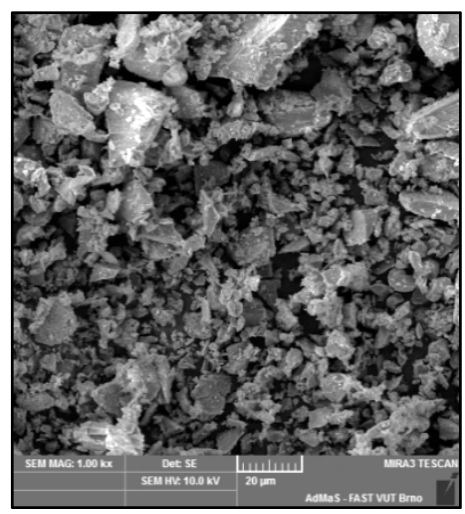

(d)

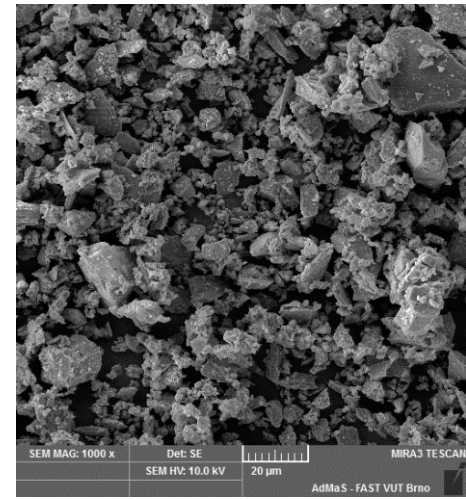

(b)

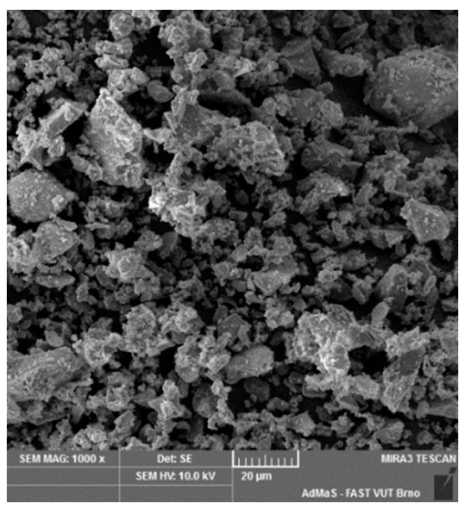

(e)

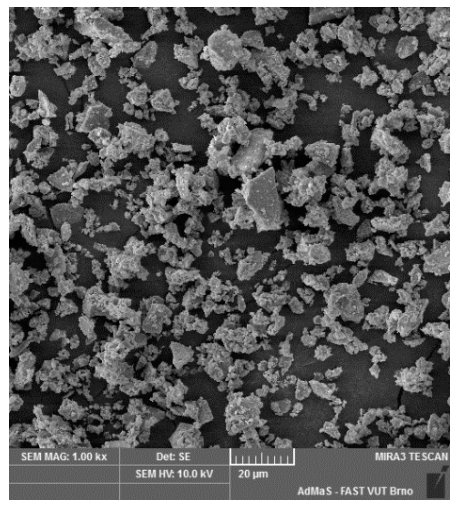

(c)

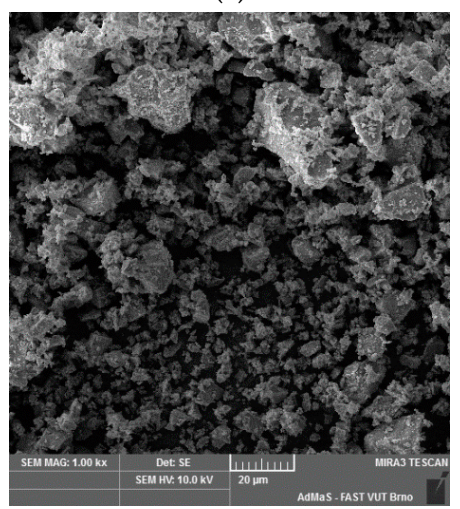

(f)

Figure 2. Comparison of the original and post-milling shapes of cement particles for: $200 \mathrm{~m}^{2} / \mathrm{kg}$ sample, (a) original particles; (d) milled particles; $300 \mathrm{~m}^{2} / \mathrm{kg}$ sample, (b) original particles; (e) milled particles; $450 \mathrm{~m}^{2} / \mathrm{kg}$ sample, (c) original particles; (f) milled particles.

The particles from the sample with the specific surface area of $200 \mathrm{~m}^{2} / \mathrm{kg}$ exhibited sharp edges, however, they were slightly abraded. Similar results were acquired for the sample with the specific surface area of $300 \mathrm{~m}^{2} / \mathrm{kg}$, but these particles exhibited a more substantial abrasion. The particles from the finest fractions then exhibited more or less spherical shapes and the tendency to agglomerate. Agglomerated clusters were also present in the sample with the initial specific surface area of $450 \mathrm{~m}^{2} / \mathrm{kg}$.

Laser granulometry revealed that the batch with the input-specific surface area of $200 \mathrm{~m}^{2} / \mathrm{kg}$ contained $20.8 \%$ of particles larger than $100 \mu \mathrm{m}$, while the batch with the input specific surface area of $450 \mathrm{~m}^{2} / \mathrm{kg}$ contained only $10.7 \%$ of particles larger than $100 \mu \mathrm{m}$. Aggregates were most probably not present because the measurements were performed under wet conditions.

The resulting specific surface areas for all the seven ground samples, together with the absolute and relative values of their increases, are depicted in Figure 3. The results show that the absolute specific surface area values increased significantly when grinding coarse fractions (specific surface areas of 200 and $250 \mathrm{~m}^{2} / \mathrm{kg}$ ). In contrast, both the absolute and relative specific surface area values were lower for the input fractions of 300 and $350 \mathrm{~m}^{2} / \mathrm{kg}$. The absolute increase in the specific surface area then increases gradually with continuing refinement of the input material, whereas the relative increase in the specific surface area remains more or less constant from the $300 \mathrm{~m}^{2} / \mathrm{kg}$ input fraction. 


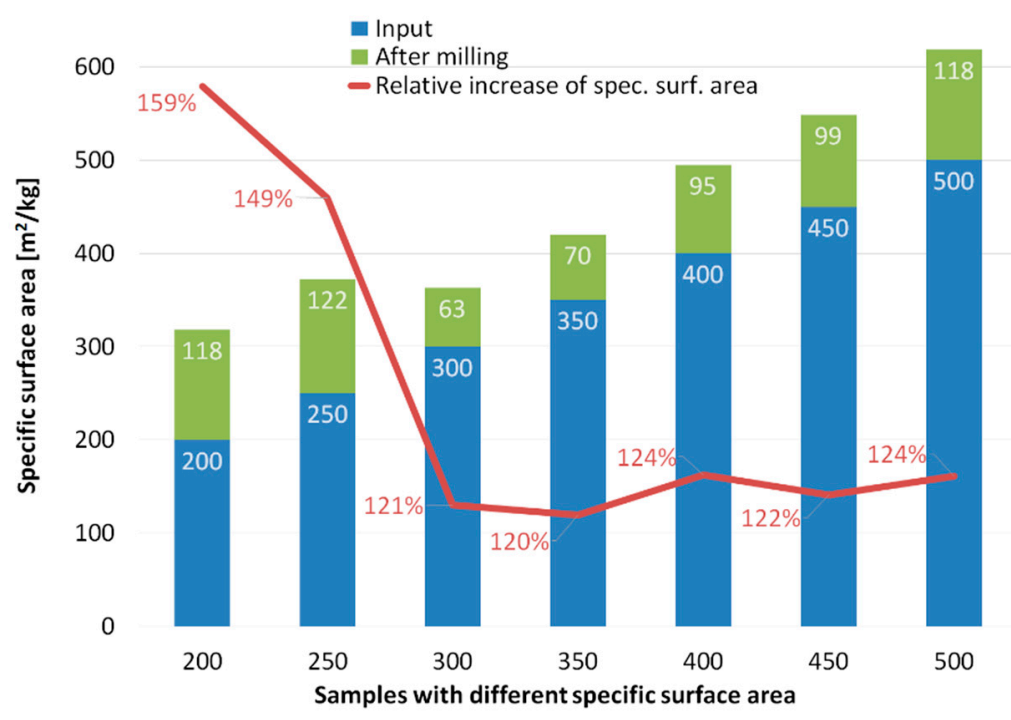

Figure 3. Increase in specific surface area for all ground samples.

Thermal imprints on the rotors before and after milling of $1 \mathrm{~kg}$ batches of $200 \mathrm{~m}^{2} / \mathrm{kg}$ to $500 \mathrm{~m}^{2} / \mathrm{kg}$ samples are shown in Figure 4a-i, respectively. The imprints clearly show that grinding of the coarse batches $\left(200\right.$ and $250 \mathrm{~m}^{2} / \mathrm{kg}$ ) was primarily performed by the front faces of the rotor pins, the temperature of which increased (Figure $4 c, d$, respectively). As the specific surface area of the input cement increased, the areas in the vicinity of the pins started to exhibit increased temperature, too. The 300, 350, and $400 \mathrm{~m}^{2} / \mathrm{kg}$ batches contained plenty of coarse particles, the grinding of which was performed directly on the rotor pins. However, mutual grinding of fine particles against each other in the spaces between the pins occurred as well. This phenomenon was then dominant for the batches with the specific surface areas of 450 , and $500 \mathrm{~m}^{2} / \mathrm{kg}$, during the milling of which the pins acted more like breaking wedges directing the milled material into the spaces between them. For these fine batches, the particles were primarily milled by their mutual collisions, and milling by direct impacts with the pins' front faces was of low significance (Figure $4 \mathrm{~h}$, i clearly show the pins to be cooler than the surrounding area).

The impact of input granulometry on wear of the grinding rotors is demonstrated by Figure 5 showing wear of the rotors (expressed as loss of rotor mass in relation to the original rotor mass) is dependent on the amount of the ground material. The figure indicates that a coarser material damages the grinding rotors of the disintegrator more significantly than a finer one.

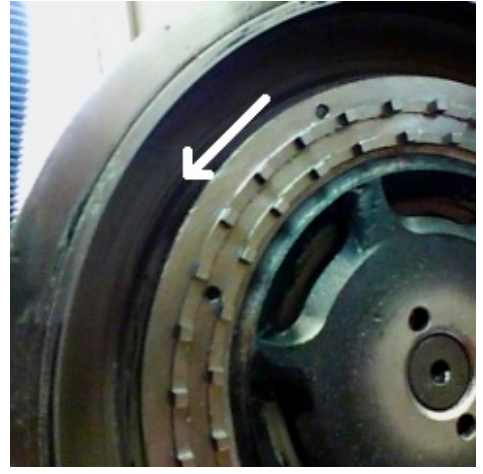

(a)

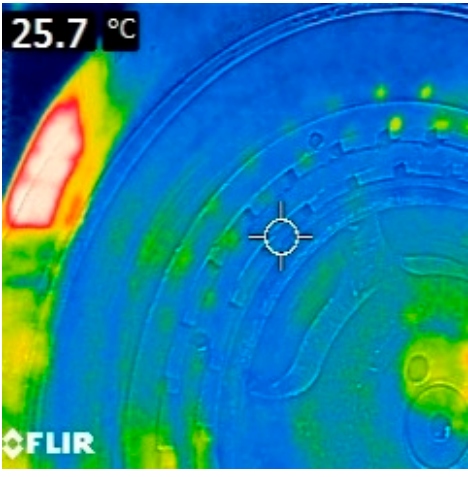

(b)

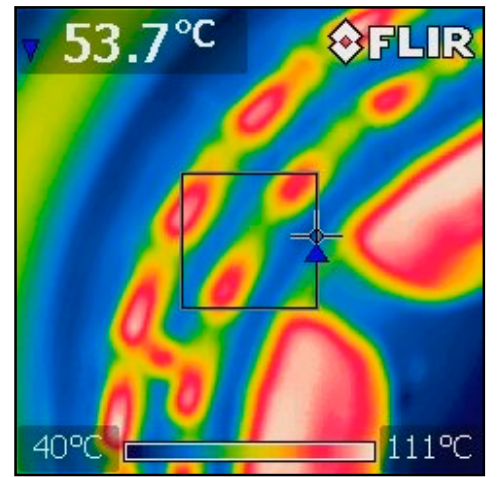

(c)

Figure 4. Cont. 


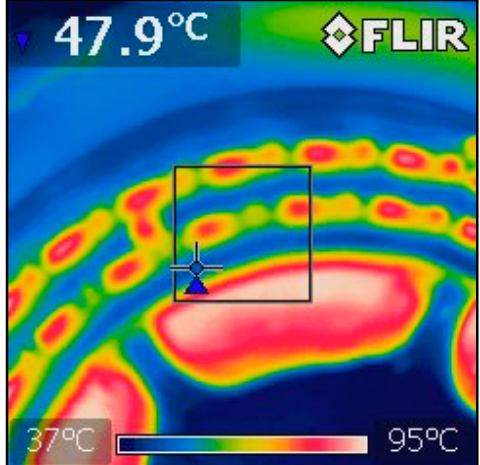

(d)

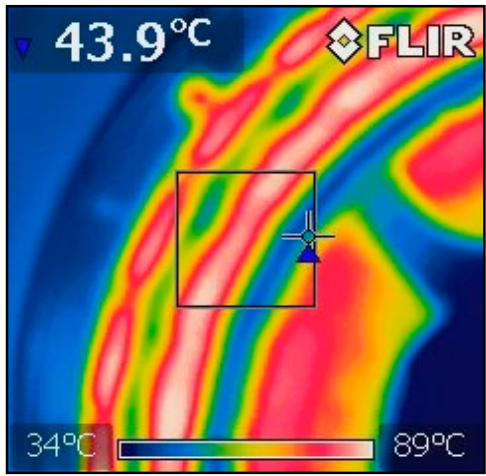

$(\mathbf{g})$

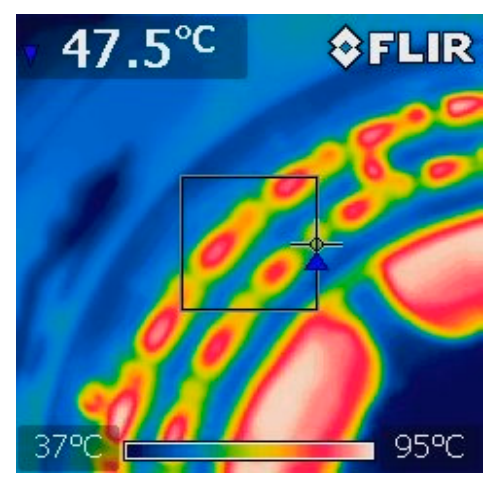

(e)

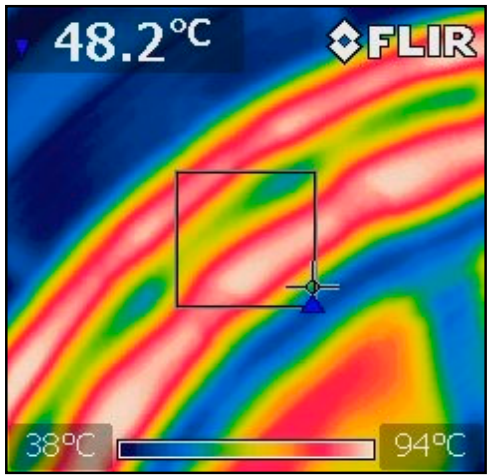

(h)

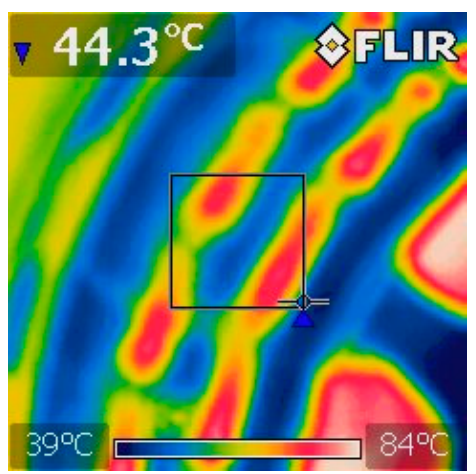

(f)

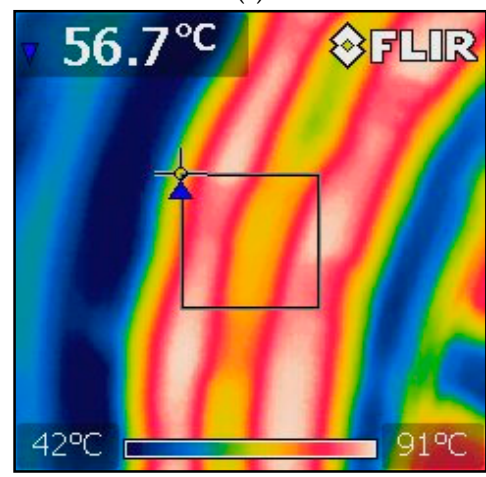

(i)

Figure 4. Thermal imprints on rotors before and after milling of $1 \mathrm{~kg}$ of individual batches: (a) new rotor with two rows of pins (rotation direction is marked by white arrow); (b) new rotor; (c) $200 \mathrm{~m}^{2} / \mathrm{kg}^{\text {; }}$ (d) $250 \mathrm{~m}^{2} / \mathrm{kg}$; (e) $300 \mathrm{~m}^{2} / \mathrm{kg}$; (f) $350 \mathrm{~m}^{2} / \mathrm{kg}$; (g) $400 \mathrm{~m}^{2} / \mathrm{kg}$; (h) $450 \mathrm{~m}^{2} / \mathrm{kg}$; (i) $500 \mathrm{~m}^{2} / \mathrm{kg}$.

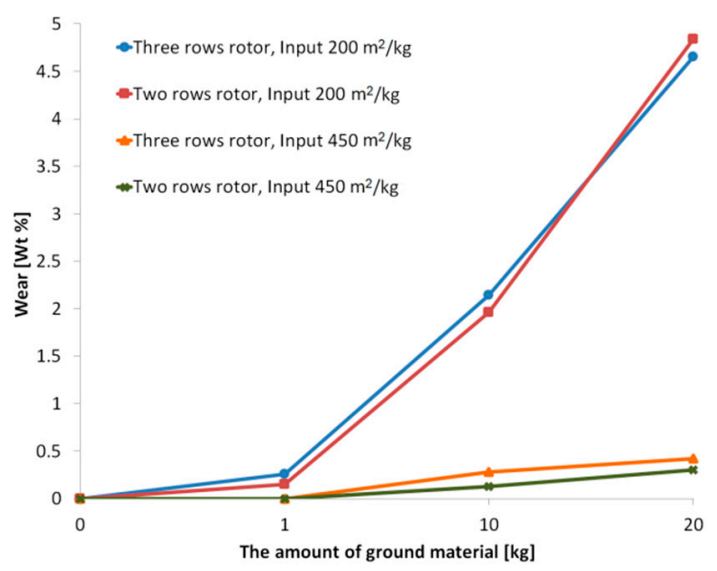

Figure 5. Effect of the amount of ground material on rotor wear for individual samples.

After milling of only a $10 \mathrm{~kg}$ batch of the testing cement with the specific surface area of $200 \mathrm{~m}^{2} / \mathrm{kg}$, the wear of the grinding rotor with three rows of pins was $2.14 \%$, and the grinding rotor with two rows of pins exhibited wear of $1.96 \%$. The wear directly influenced the increase in the specific surface area of particles, as the grinding was about $1.61 \%$ less effective. Table 2 summarizes the results of measurements of the specific surface area for the cement powder at the beginning of the experiment, and after milling of 10 and $20 \mathrm{~kg}$ batches. Table 3 then presents the reductions of grinding efficiency, characterized as reduction of the specific surface area. When grinding the fine-grained input material with the specific surface area of $450 \mathrm{~m}^{2} / \mathrm{kg}$, the abrasion occurred to a lesser extent. The weight loss measured for the rotor with three rows of pins after grinding of a $10 \mathrm{~kg}$ batch was $0.28 \%$, while for the rotor with two rows of pins it was $0.13 \%$; the reduction of the efficiency of grinding by the worn rotors 
was negligible. Milling of a $20 \mathrm{~kg}$ batch of the testing cement resulted in further rotor weight loss; after grinding an additional $10 \mathrm{~kg}$ batch, the weight loss of the three-row rotor was $0.42 \%$, while for the two-row rotor it was only $0.30 \%$. The efficiency of the rotors was only $1.28 \%$ lower when compared to new rotors.

Table 2. Specific surface area of the cement powder at the beginning and after 10 and $20 \mathrm{~kg}$.

\begin{tabular}{cccc}
\hline Input Specific Surface Area $\left(\mathbf{m}^{\mathbf{2}} / \mathbf{k g}\right)$ & \multicolumn{4}{c}{ Specific Surface Area of Resulting Powders $\mathbf{( \mathbf { m } ^ { 2 } / \mathbf { k g } )}$} \\
\hline & $\mathbf{1} \mathbf{~ k g}$ & $\mathbf{1 0} \mathbf{~ k g}$ & $\mathbf{2 0 ~} \mathbf{~ g}$ \\
\hline 200 & 310 & 305 & 273 \\
450 & 548 & 543 & 541 \\
\hline
\end{tabular}

Table 3. Reduction of grinding efficiency.

\begin{tabular}{cccc}
\hline Input Specific Surface Area $\left(\mathbf{m}^{\mathbf{2}} / \mathbf{k g}\right)$ & \multicolumn{3}{c}{ Grinding Efficiency Reduction (\%) } \\
\hline & $\mathbf{1 ~} \mathbf{~ k g}$ & $\mathbf{1 0 ~} \mathbf{~ g g}$ & $\mathbf{2 0 ~} \mathbf{~ k g}$ \\
\hline 200 & - & 1.61 & 11.94 \\
450 & - & 0.91 & 1.28 \\
\hline
\end{tabular}

Figure $6 \mathrm{a}-\mathrm{h}$ show 3D optical microscopy images of the new and worn rotor pins. All the scans were performed on the rotors with three rows of pins. Figure $6 \mathrm{a}, \mathrm{b}$ depict the 3D scan and height profile, respectively, of the pins of a new rotor, while Figure $6 c, d$ depict the 3D scan and height profile, respectively, of the pins of the rotor used for milling of a $20 \mathrm{~kg}$ batch of the $450 \mathrm{~m}^{2} / \mathrm{kg}$ sample. Figure $6 \mathrm{e}, \mathrm{f}$ then depict the 3D scan and height profile, respectively, of the pins of the rotor used for the milling of a $20 \mathrm{~kg}$ batch of the $200 \mathrm{~m}^{2} / \mathrm{kg}$ sample. The figures confirm the wear analyses, as they clearly show that the wear was the most significant for the rotor used for milling of the $200 \mathrm{~m}^{2} / \mathrm{kg}$ batch; scans of a pin from the most worn rotor and its coloured height profile are shown in Figure $6 \mathrm{~g}$,h. The figures also show that the wear of the pins was the most significant at their front faces, and also at the face on the side from which the cement particles were injected into the disintegrator. The figures also show evident "shade" behind the pins, which corresponds to the above described occurring milling mechanisms for the individual sample batches.

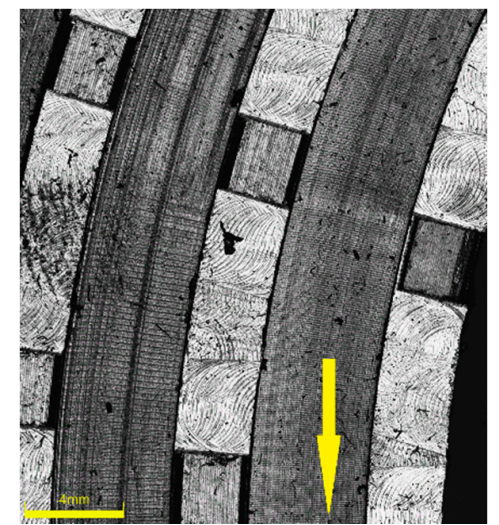

(a)

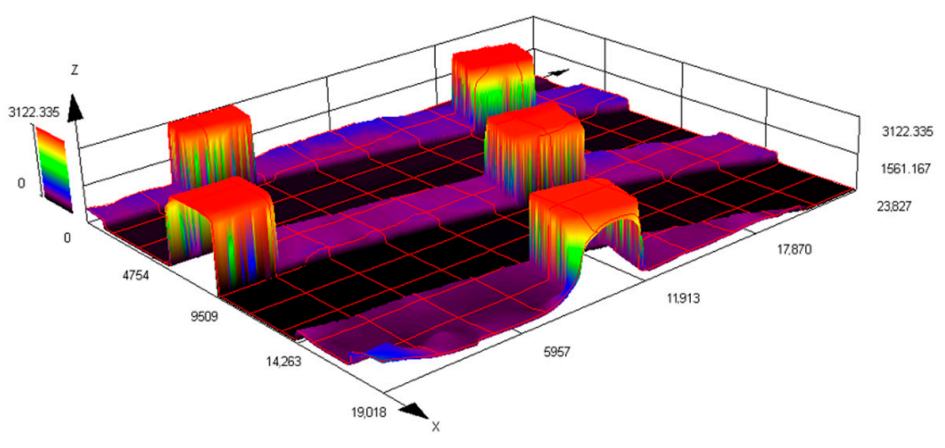

(b)

Figure 6. Cont. 


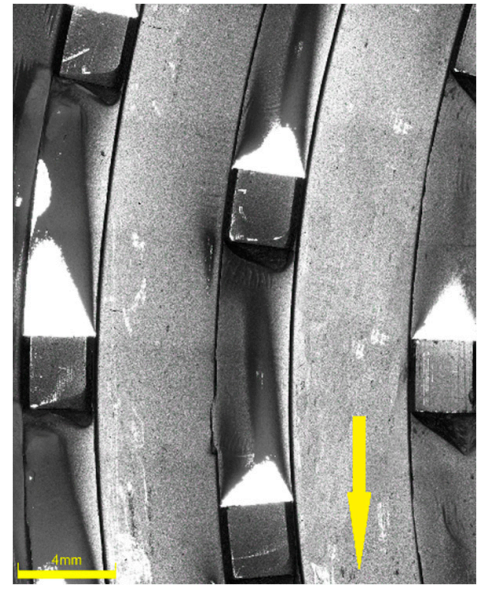

(c)

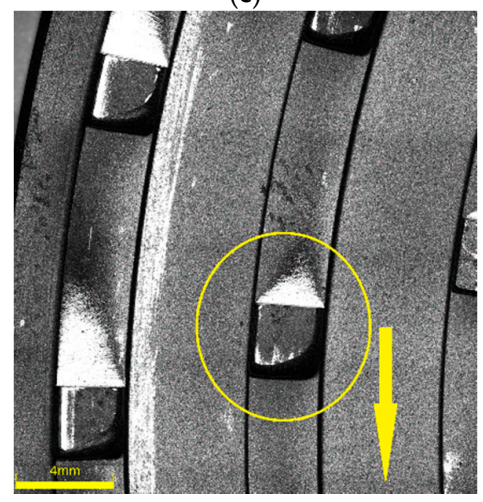

(e)

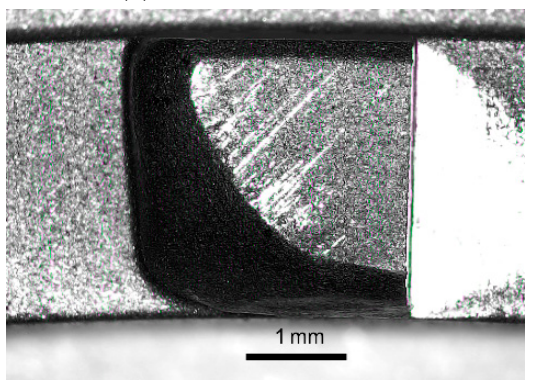

(g)

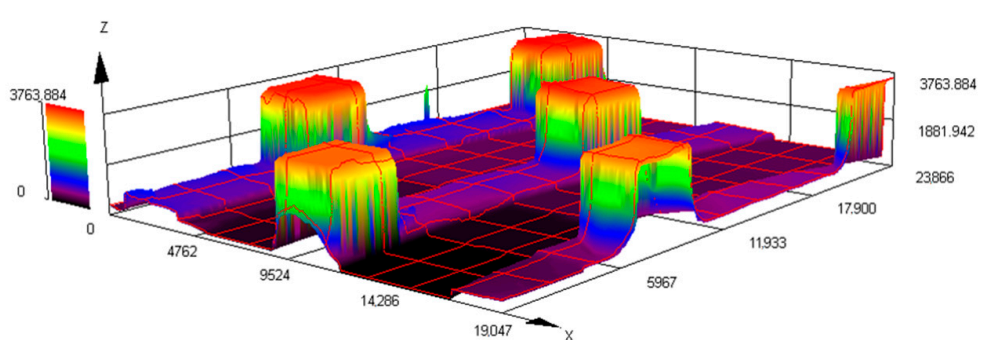

(d)

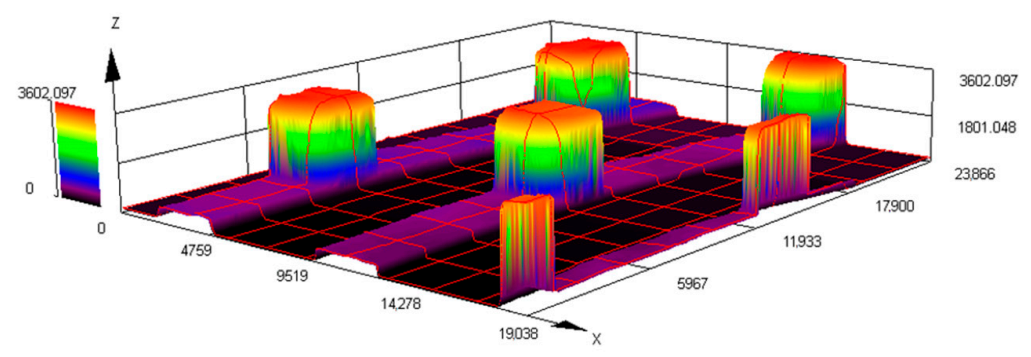

(f)

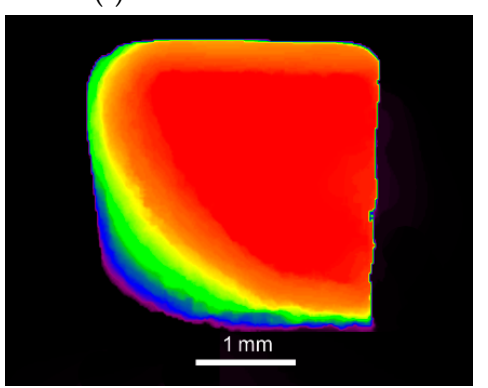

(h)

Figure 6. Optical images of new rotor: (a) 3D scan and (b) height profile of pins; optical images of rotor used for milling of $20 \mathrm{~kg}$ batch of $450 \mathrm{~m}^{2} / \mathrm{kg}$ sample: (c) 3D scan and (d) height profile of pins; optical images of rotor used for milling of $20 \mathrm{~kg}$ batch of $200 \mathrm{~m}^{2} / \mathrm{kg}$ sample: (e) 3D scan and (f) height profile of pins. Detailed images of pin marked by circle in (f) from rotor used for milling of $20 \mathrm{~kg}$ batch of $200 \mathrm{~m}^{2} / \mathrm{kg}$ sample: (g) detailed scan and (h) coloured profile. (Rotation directions marked by arrows).

\section{Discussion}

The different acting particle grinding principles imparted by different input granulometries have considerable effects on the abrasion of the grinding rotors, especially the pins. When milling the samples with the input-specific surface areas of 200 and $250 \mathrm{~m}^{2} / \mathrm{kg}$, the pins of the grinding rotors are strongly heated due to the direct contact with the material being ground, as confirmed by the thermal imprints shown in Figure $4 a, b$. The direct crushing and friction of the coarse particles on the front faces of the rotor pins also resulted in a substantial increase in the specific surface areas of the particles. The negative aerodynamic pressure occurring right behind the rotor pins is not sufficient to impart swirling motion to the solid particles. For this reason, the particles are not milled by mutual collisions and thus maintain their sharp-edged morphology during passing through the mill; only 
a slight abrasion of their edges occurs. The wear of the rotors was the highest for these batches and expressed as mass \% of the original rotor mass was almost $5 \%$ for both the rotors with two and three rows of pins. The shapes of the rotor pins were also severely damaged after milling of the batches with coarse particles, as demonstrated in Figure $6 \mathrm{e}-\mathrm{h}$. These findings are in accordance with the theory of Misra and Finnie [31]; large particles impact the front faces of the pins, easily penetrating the surface layers, and cause rapid erosion.

The results acquired during grinding of the samples with very fine particles having the specific surface areas of over $400 \mathrm{~m}^{2} / \mathrm{kg}$ were different; the cement particles exhibited intensive refinement and gained spherical shapes, however, they also exhibited a tendency to agglomerate. The momentum of the particles is sufficiently low for them to be drawn into the area of lower pressure in the space behind the rotor pins; the pins act more like breaking wedges and regulate the material flow. The milling is primarily performed by mutual particle collisions in the turbulent area right behind the rotor pins, as demonstrated by the thermal imprints on the rotors in Figure $4 \mathrm{e}-\mathrm{g}$, the locations with the highest temperatures in which were situated behind the rotor pins. In contrast to the coarse samples, the finer material with the specific surface area of $450 \mathrm{~m}^{2} / \mathrm{kg}$ flows around the pins. Thus small particles do not penetrate the surface layer of the grinding pins and the wear on the rotors is significantly lower for the fine samples. The 3D profiles of the rotor pins depicted in Figure $6 c$,d exhibited only a slight abrasion, which is consistent with the measured wear being lower than $0.5 \%$ of the original rotor mass.

Characterization of the grinding process for the batches featuring the input specific surface areas of 300 to $350 \mathrm{~m}^{2} / \mathrm{kg}$ is quite complex. Increases in the specific surface areas for these samples were lower than for the other, coarser as well as finer, batches. The thermal imprints depicted in Figure $4 \mathrm{c}, \mathrm{d}$ show that a portion of the ground material is in direct contact with the front faces of the grinding pins. Nevertheless, an increase in the temperature in the spaces between and behind the rotor pins is observed as well. This phenomenon implies that during milling of these samples, reduction of particles' sizes proceeds not only via direct contact with the rotor pins, but also, to some extent, via mutual collisions of the particles behind the grinding pins. The amount of coarse grains that are ground on the front surfaces of the rotor pins is lower than for coarser samples. At the same time, the amount of fine grains that have lower momentum and are milled by mutual collisions is not sufficient. The total increase in the specific surface area is thus lower than for the finer and coarser samples. The sharp edges of the particles are abraded after passing through the mill, however, the shape of the coarse particles does not change significantly. For these reasons, assessment of the surface hardening effect for these particular batches would require a deeper study.

\section{Conclusions}

A variety of modern materials with enhanced properties is nowadays fabricated via methods of powder metallurgy, the initial powders for which are typically manufactured using milling machines. This study focused on the characterization of the performance of a DESI 11 high-speed disintegrator. For the purpose of the study, a variety of samples of Portland cement, containing relatively hard and abrasive particles with specific surface areas ranging from 200 to $500 \mathrm{~m}^{2} / \mathrm{kg}$, were used. The results showed that:

- Grinding of coarse angular-shaped particles proceeds primarily via impacts of particles with the front faces of rotor pins, and such particles cause their significant damage and abrasion.

- $\quad$ Fine cement particles are refined in the area between and behind the pins. This grinding principal supports wear reduction and the grinding efficiency is not substantially affected when milling larger batches of finer cement samples.

- Without sustaining significant damage, this type of high-speed mill is suitable for final grinding of fine particles with the Blaine specific surface area of at least $400 \mathrm{~m}^{2} / \mathrm{kg}$.

- Coarser materials can be ground more efficiently in other types of mill. 
- A reasonable specific surface increase with minimum wear of the grinding tools can be achieved in a relatively short time for materials with suitable input granulometries.

The high-speed disintegrator is, thus, an advantageous, versatile piece of equipment for the preparation of powders subsequently used to prepare modern materials.

Author Contributions: Conceptualization, K.D.; methodology, K.D.; software, A.M.; validation, D.G.; formal analysis K.D.; investigation, K.D. and S.R.; resources K.D.; data curation, K.D., A.M., D.G. and S.R.; writing_original draft preparation, K.D.; writing—review and editing, A.M.; visualization, D.G. and S.R.; supervision, K.D.; project administration, K.D. and A.M.; funding acquisition, K.D. and A.M. All authors have read and agreed to the published version of the manuscript.

Funding: We acknowledge the financial support of Czech Science Foundation under the project "Effects of mechano-chemical activation on the process of formation, structure and stability of selected clinker minerals" (20-00676S), and FV40286 Ministry of Industry and Trade TRIO programme.

Acknowledgments: The authors would like to thank Lenka Kunčická for her help with analysing the rotors.

Conflicts of Interest: The authors declare no conflict of interest.

\section{References}

1. Thomasová, M.; Seiner, H.; Sedlák, P.; Frost, M.; Ševčík, M.; Szurman, I.; Kocich, R.; Drahokoupil, J.; Šittner, P.; Landa, M. Evolution of macroscopic elastic moduli of martensitic polycrystalline NiTi and NiTiCu shape memory alloys with pseudoplastic straining. Acta Mater. 2017, 123, 146-156. [CrossRef]

2. Leo Samuel, D.G.; Dharmasastha, K.; Shiva Nagendra, S.M.; Maiya, M.P. Thermal comfort in traditional buildings composed of local and modern construction materials. Int. J. Sustain. Built Environ. 2017, 6, 463-475. [CrossRef]

3. Naser, M.Z. Properties and material models for modern construction materials at elevated temperatures. Comput. Mater. Sci. 2019, 160, 16-29. [CrossRef]

4. Kunčická, L.; Kocich, R. Comprehensive characterisation of a newly developed Mg-Dy-Al-Zn-Zr alloy structure. Metals 2018, 8, 73. [CrossRef]

5. Zhang, P.; Li, Z.; Liu, B.; Ding, W. Effect of chemical compositions on tensile behaviors of high pressure die-casting alloys Al-10Si-yCu-xMn-zFe. Mater. Sci. Eng. A 2016, 661, 198-210. [CrossRef]

6. Edalati, K.; Cubero-Sesin, J.M.; Alhamidi, A.; Mohamed, I.F.; Horita, Z. Influence of severe plastic deformation at cryogenic temperature on grain refinement and softening of pure metals: Investigation using high-pressure torsion. Mater. Sci. Eng. A 2014, 613, 103-110. [CrossRef]

7. Kunčická, L.; Kocich, R.; Král, P.; Pohludka, M.; Marek, M. Effect of strain path on severely deformed aluminium. Mater. Lett. 2016, 180, 280-283. [CrossRef]

8. Verlinden, B.; Driver, J.; Samajdar, I.; Doherty, R.D. Thermo-Mechanical Processing of Metallic Materials; Elsevier: Amsterdam, The Netherlands, 2007; ISBN 9780080444970.

9. Kunčická, L.; Kocich, R.; Drápala, J.; Andreyachshenko, V.A. FEM simulations and comparison of the ecap and ECAP-PBP influence on Ti6Al4V alloy's deformation behaviour. In Proceedings of the Metal 2013: 22nd International Conference on Metallurgy and Materials, Brno, Czech Republic, 15-17 May 2013; pp. 391-396.

10. Kunčická, L.; Lowe, T.C.; Davis, C.F.; Kocich, R.; Pohludka, M. Synthesis of an Al/Al2O3composite by severe plastic deformation. Mater. Sci. Eng. A 2015, 646, 234-241. [CrossRef]

11. Joshi, P.B.; Marathe, G.R.; Murti, N.S.S.; Kaushik, V.K.; Ramakrishnan, P. Reactive synthesis of titanium matrix composite powders. Mater. Lett. 2002, 56, 322-328. [CrossRef]

12. Kunčická, L.; Macháčková, A.; Lavery, N.P.; Kocich, R.; Cullen, J.C.T.; Hlaváč, L.M. Effect of thermomechanical processing via rotary swaging on properties and residual stress within tungsten heavy alloy. Int. J. Refract. Met. Hard Mater. 2020, 87, 105120. [CrossRef]

13. Stolyarov, V.V.; Zhu, Y.T.; Lowe, T.C.; Islamgaliev, R.K.; Valiev, R.Z.R. Processing nanocrystalline Ti and its nanocomposites from micrometer-sized Ti powder using high pressure torsion. Mater. Sci. Eng. A 2000, 282, 78-85. [CrossRef]

14. Kunčická, L.; Kocich, R.; Hervoches, C.; Macháčková, A. Study of structure and residual stresses in cold rotary swaged tungsten heavy alloy. Mater. Sci. Eng. A 2017, 704, 25-31. [CrossRef] 
15. Wang, X.; Chen, Y.; Xu, L.; Xiao, S.; Kong, F.; Woo, K. Do Ti-Nb-Sn-hydroxyapatite composites synthesized by mechanical alloying and high frequency induction heated sintering. J. Mech. Behav. Biomed. Mater. 2011, 4, 2074-2080. [CrossRef]

16. Macháčková, A.; Krátká, L.; Petrmichl, R.; Kunčická, L.; Kocich, R. Affecting Structure Characteristics of Rotary Swaged Tungsten Heavy Alloy Via Variable deformation temperature. Materials 2019, 12, 4200. [CrossRef] [PubMed]

17. Surzhenkov, A.; Viljus, M.; Simson, T.; Tarbe, R.; Saarna, M.; Casesnoves, F. Wear resistance and mechanisms of composite hardfacings at abrasive impact erosion wear. J. Phys. Conf. Ser. 2017, 843, 012060. [CrossRef]

18. Muroi, M.; Street, R.; McCormick, P.G. Structural and Magnetic Properties of Ultrafine La0.7Ca0.3MnOz Powders Prepared by Mechanical Alloying. J. Solid State Chem. 2000, 152, 503-510.

19. Razavi Tousi, S.S.; Yazdani Rad, R.; Salahi, E.; Mobasherpour, I.; Razavi, M. Production of Al-20 wt.\% Al2O3 composite powder using high energy milling. Powder Technol. 2009, 192, 346-351. [CrossRef]

20. Serena, S.; Caballero, A.; Turrillas, X.; Martin, D.; Sainz, M.A. Effect of ceramic nanoparticles on the solid-state reaction mechanism of dolomite-zirconium oxide followed by neutron thermodiffraction measurements. J. Nanopart. Res. 2009, 11, 869-878. [CrossRef]

21. Rojac, T.; Kosec, M.; Malič, B.; Holc, J. Mechanochemical synthesis of NaNbO3. Mater. Res. Bull. 2005, 40, 341-345. [CrossRef]

22. Hint, J. Fundamentals of Silicalcite Production; Strojizdat: Moscow, Russia, 1962. (In Russian)

23. Bumanis, G.; Bajare, D.; Goljandin, D. Performance evaluation of cement mortar and concrete with incorporated micro fillers obtained by collision milling in disintegrator. Ceram. Silik. 2017, 61, $231-243$. [CrossRef]

24. Bumanis, G.; Bajare, D. Compressive Strength of Cement Mortar Affected by Sand Microfiller Obtained with Collision Milling in Disintegrator. Procedia Eng. 2017, 172, 149-156. [CrossRef]

25. Kovalev, P.I. Influence of shock destruction of solid and liquid particles in the supersonic flow around a solid two-phase flow. J. Appl. Phys. 2008, 78, 40-46.

26. Baláž, P. High-Energy Milling. In Mechanochemistry in Nanoscience and Minerals Engineering; Springer: Berlin/Heidelberg, Germany, 2008; pp. 103-132.

27. Starman, B.; Hallberg, H.; Wallin, M.; Ristinmaa, M.; Halilovič, M. Differences in phase transformation in laser peened and shot peened 304 austenitic steel. Int. J. Mech. Sci. 2020, 176, 105535. [CrossRef]

28. Silva, K.H.S.; Carneiro, J.R.; Coelho, R.S.; Pinto, H.; Brito, P. Influence of shot peening on residual stresses and tribological behavior of cast and austempered ductile iron. Wear 2019, 440-441, 203099. [CrossRef]

29. Han, X.; Zhang, Z.; Hou, J.; Barber, G.C.; Qiu, F. Tribological behavior of shot peened/austempered AISI 5160 steel. Tribol. Int. 2020, 145, 106197. [CrossRef]

30. Misra, A.; Finnie, I. On the size effect in abrasive and erosive wear. Wear 1981, 65, 359-373. [CrossRef]

31. Larsen-Badse, J. Influence of grit diameter and specimen size on wear during sliding abrasion. Wear 1968, 12, 35-53. [CrossRef]

32. Gåhlin, R.; Jacobson, S. The particle size effect in abrasion studied by controlled abrasive surfaces. Wear 1999, 224, 118-125. [CrossRef]

33. Hewlett, P. Lea's Chemistry of Cement and Concrete; Elsevier: Amsterdam, The Netherlands, 2004; ISBN 9780750662567.

(C) 2020 by the authors. Licensee MDPI, Basel, Switzerland. This article is an open access article distributed under the terms and conditions of the Creative Commons Attribution (CC BY) license (http://creativecommons.org/licenses/by/4.0/). 